\title{
'NEW KIDS ON THE BLOCK': DEVELOPING A SOCIAL SCIENCE STRATEGY IN THE BRITISH LIBRARY
}

\author{
Jude England
}

\section{INTRODUCTION}

The British Library plays a major role in supporting the UK's research infrastructure and in 2004 identified the provision of research-led information and resources to the social science research community - users, producers and commissioners - as a key area for future emphasis. Our work since then to develop and implement a dedicated social science strategy in a national library suggests that the age of inter-, multi- and even trans-disciplinary research has arrived. Moreover, social scientists are eclectic in their use of research material and methodologies - the best of them, very much so. There are, however, considerable variations in the attitude and approach of researchers in different disciplines, including their desire to collaborate. Funding pressures create intense competition, which militates against collaboration. Furthermore, our informal discussions with researchers suggest that there is a tendency at times to launch into primary research without adequate review of previous research. Research carried out by the Library in 2008 suggests that the ease of access to material via internet search engines creates researchers who 'view' rather than 'mine' information ${ }^{1}$.

From the perspective of a national library which began its formal existence in 1753, many of the disciplines sitting under the social science umbrella are relatively new. Inevitably, social scientists are viewed as the 'new kids on the block'; as a result there is little organisational knowledge about what they research, study and contribute. It is also important to note that historically the Library has thought in terms of its 'collections' which are defined by format and location/country of origin, rather than content or theme. Conversely, social scientists are much less interested in how the information comes, or where it is from, unless these issues are the specific subject of their research; one of our key challenges has been, therefore, to develop relationships with our colleagues in other collection areas to facilitate access to the wealth of content in the Library.

This background forms some of the context to the task of developing a social science strategy in the British Library (referred to the BL and the Library in abbreviation). My paper discusses the processes and issues involved in its early development, looking at the period autumn 2006 to summer 2008. The views expressed in it, and any errors, are the author's own ... 


\section{THE BRITISH LIBRARY}

The history of the British Library as the national repository of the UK's social and cultural life begins in 1753, when the British Museum Act charged the British Museum Library to care for books, manuscripts and papers acquired by the State and make them available for 'publick use to all prosperity'. The content of the Library evolved organically, rather than systematically until the mid $19^{\text {th }}$ century, when legal deposit was actively enforced.

The British Library itself came into formal existence in 1972 via another Act of Parliament which brought together a number of national information institutions, with a wide range of functions and cultures. The Library did not have a major physical presence until 1998, when it moved into the St Pancras building, Even now, activity is split over a number of geographically disparate sites.

The Library holds some 170 million items, including over 13 million books, 57 million patents, almost 5 million items of grey literature, nearly 60,000 newspaper titles, and 3 million sound recordings. There are comprehensive collections of UK, US and European official publications, medieval to modern manuscripts, oral history, and, extensive collections from a range of intergovernmental organisations (e.g. UN, OECD). The Library has wide-ranging historical and contemporary international collections, and is building a UKdomain web archive.

The St Pancras building provides reading rooms for access to the collection material; there is also a significant public space, including exhibition areas and a conference centre.

The Library exists to support all researchers, whatever their background and purpose. This policy was implemented in 2004; until then use was dependent on proving a genuine research need and tended to be limited to scholarly researchers. Demand for reader passes since 2004 has increased year-on-year, but large parts of the research community still know little about the resources available.

\section{DEVELOPMENT OF A SOCIAL SCIENCE STRATEGY}

7. In 2004 a review was carried out of the Library's services to social science researchers. The decision to do so arose from a general perception that the social sciences were being marginalized at the expense of other subject areas. The review's findings pointed to the existence of strong foundations such as plentiful research-level material, a dedicated reference team and reading room. Researchers could access interlibrary loan and document supply services, and key collection development partnerships were in place. 
Less positively, the review found that the Library had few links with social science research communities and that their knowledge of the Library was minimal. It also concluded that there was only patchy internal awareness of social science research and the needs of researchers, and, that the Library was not using its resources as much as it could to support the research community with dissemination and knowledge exchange.

The report recommended that the Library develop a specific strategy placing emphasis on collaboration with key partners, and on exploitation of our collections, expertise and resources to promote and enrich inter- and crossdisciplinary exchange. It also pointed to the need to strengthen resource discovery and build expertise and skills within the Library to enable us to understand and meet researchers' needs.

The British Library Board approved the recommendation for the creation of Social Science Collections and Research (SSCR) at the beginning of 2006, and a new head of department joined the Library at the end of September the same year. The first task was to build the team - which grew from four full time equivalents (fte) in October 2006 to $15 \mathrm{fte}$ in January 2008.

\section{THE SCOPE OF THE UK SOCIAL SCIENCE, RESEARCH AND ACADEMIC ENVIRONMENT}

As a major national research library we have a wide user community - actual and potential - and need to be aware of their requirements. Also critical is awareness of the major policy and funding drivers for research as they influence need and demand for information. This is not a straightforward task as the scope of social science disciplines is wide, ranging from sociology, politics, business and management studies, economics and economic development, to human geography, education, psychology and linguistics. Also key are social policy, social work, anthropology, law, international studies, and government. Furthermore, for the Economic and Social Research Council, statistics, computing, infrastructure, demography, research methodology and capacity building are increasingly important.

As well as disciplines, the development of our offer must take into account the key research drivers. The Economic and Social Research Council (ESRC) ${ }^{2}$ identifies eight research themes in its delivery plan for 2008-11; alongside these are a number of - mostly complementary - UK government concerns set out by the Cabinet Office Strategy $\operatorname{Unit}^{3}$ (Table 1). These themes determine the direction of most research funding. 
Table 1: Key UK research themes

ESRC Delivery Plan themes 2008-11

Succeeding in the global economy

Migration and Population Change

Understanding individual behaviour

Energy

Living with Environmental Change

Terrorism, Security, Global Conflict and Uncertainty

Lifelong health and well-being

Digital Economy

\section{UK Government Concerns}

Globalisation

Ageing and population diversity

Economic prosperity

Family life and communities

Climate change

Crime and public safety

Life chances, talent and social mobility

Modernisation and renewal of the constitution and democratic institutions

UK research is carried out in a wide range of organisations including higher education institutions (HEIs) ${ }^{4}$, government and related bodies (central and local), research institutes, and the third ${ }^{5}$ and private sectors ${ }^{6}$. Many social science researchers move to work in professions like market research, advertising and public relations. Market research organisations in the UK are themselves an important supplier of social research services.

\section{Research funding}

Funding for social science research in the UK comes from a wide range of sources, including the ESRC, philanthropic foundations, central and local government bodies, and, some major corporate organisations, who support research activity through their corporate social responsibility arms.

Access to funding is uneven - and competition is fierce - within the academic sector, between the academic sectors and others. Researchers outside academic institutions tend not to have access to resources available from the ESRC and the major foundations so tend to be even fiercer rivals for research commissions and scarce resources.

\section{Current issues for the UK social science research community}

The use of evidence-based research and evaluation to support policy and programme development has increased enormously in the last 10-15 years within the UK, accompanied by a comparable increase in the size of the non-HE based research community. Not all researchers welcome this emphasis on a thematic, policy-driven, evidence-based research funding regime rather than 'pure' re- 
search; some (particularly academics) resent fitting their interests to a set agenda in order to obtain funding. However, things are likely to get tighter given the economic downturn of 2008/09 and the possible change of government in 2010 .

Researchers also face the issue of managing the 'information and data deluge', while at the same time seeing the loss of dedicated information services as non-academic institutions cut back on information and library services - one researcher recently commented that her own use of the British Library had increased with the closure of her in-house library. Many researchers are simply doing less systematic background and contextual research on issues as a result. There is a growing trend for researchers to be 'time poor' and liable to want information immediately, to their desks; the Library's recent research on the behaviour of the 'e-generation' found that researchers as a whole - no matter what their chronological age - have developed a 'viewing' rather than 'mining' tendency when using the internet.

Finally, two other issues are having an impact on the research environment. First, there are growing concerns about the recruitment and retention of researchers. Some research areas are supported by an ageing community, increasing the importance of capacity building and knowledge transfer. Second, research councils and government are placing increased emphasis on dissemination and the impact and value of research, in particular, how to enhance public understanding of its purpose and outcome.

\section{THE BRITISH LIBRARY AND SOCIAL SCIENCE IN 2008}

The review of social science carried out in 2004 found that knowledge of the British Library was highest among academic researchers. This was not surprising as at this point access to the Library was dependent on proof of research need - most non-academic researchers simply assumed that its services were not for them. In 2008, two thirds of existing British Library readers continued to be from academic institutions, but our share of the potential population of social science post-graduates was small; just five per cent of over 300,000 post-graduates were readers, compared to almost a quarter of the eligible population in Arts and Humanities.

A survey of the users of the social science reading room in February 2007 found that almost three quarters of them were from higher education. A quarter were undergraduates; a fifth research postgraduates; around one in ten taught postgraduates; and the same proportion, teaching staff. Just a quarter of users were not from the academic community, and only a very small proportion of them were from the broader research community in government, nongovernmental organisations, research libraries and professional associations, plus consultancies, funders and so on. This was an untapped audience in 2004 and remains so. 
Findings from a scoping study of the collections ${ }^{7}$, and our focus groups with social science researchers ${ }^{8}$ reinforced the earlier evidence from research carried out for the review in $2004^{9}$ that awareness of the content - and potential - of the Library was minimal among researchers as a whole, no matter what type of institution they were based in.

Furthermore, many of the researchers we spoke to in 2007 and 2008 - academics and others - did not realise they were entitled to use the Library.

Another issue emerged from our initial information-gathering activities: academic researchers were not interested in using the Library to access conventional e-resources such as journals and datasets as they have easy access to these through their home institutions. Conversely, researchers in non-governmental organisations have a much greater need for this type of material as they have less economic capacity and 'clout', but are time-poor and more likely to want remote access. This poses a real conundrum for the Library as most access to e-resources is through license and can only take place on site.

\section{Scoping Study of the Collections}

In late 2006, we signed a strategic partnership agreement with the ESRC. The purpose of this agreement is to:

'... promote effective interaction between the BL and the ESRC in the development of their activities and plans for the improvement of information services for researchers.'

One immediate output of the partnership was the funding for the scoping study of the collections already mentioned. It was carried out in the summer of 2007 and involved three workshops, attended by 34 researchers from a variety of research interests and, a quantitative survey completed by some 200 researchers.

The study confirmed that levels of awareness and familiarity with the Library and the potential of its collections was low; little use was made of the broad range of resources (Table 2) and just a fifth of the respondents had a readers pass. Levels of awareness were low even among these researchers who might be expected to draw on the Library's extensive collections of UK official publications and those of international non-governmental organizations such as the European Community, the World Bank, UN and OECD. In fact, one of the workshop participants was writing a book on the World Bank and had not known about the Library's holdings in this area. 
Table 2: Use of the British Library's resources

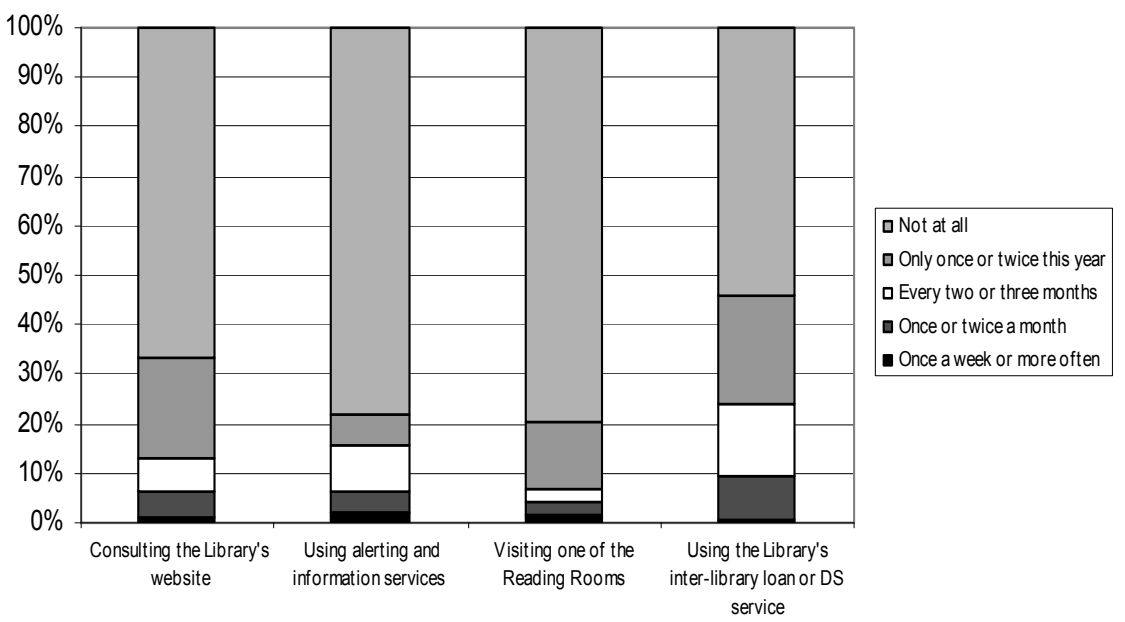

The study identified a number of additional barriers to, and constraints on, use of the collections at the Library. These included physical location, time, distance and cost of access, plus the lack of easily accessible information about the services provided. Many of the respondents to the study felt that the range, depth and organisation of the collections were daunting and did not offer an 'easy way in'; finding aids and resource discovery were described as inadequate.

Not all was gloomy - even participants in the study with little experience of the Library identified its strengths. They recognised the possibilities inherent in the historical depth and geographical strength of the collections, plus the range of subjects and formats. The availability of official publications, government statistics and publications from international and multi-national organisations was also valued.

The research collected views on developments that would encourage use of the Library (Table 3). Predictably, enabling remote access to material was at the top of the list but around six out of ten were keen to see improved online searching facilities. The same proportion recommended the production of research-led topic guides to the collection (both print and online), about half were interested in improved research and current awareness services, and almost half responded positively to a suggestion of BL mediated research communities. Four out of ten were interested in receiving information on collections not held by the BL, and a similar proportion in one-to-one advisory services to assist with research. But only a fifth were interested in research skills training. 
Table 3: Developments to encourage use of the British Library

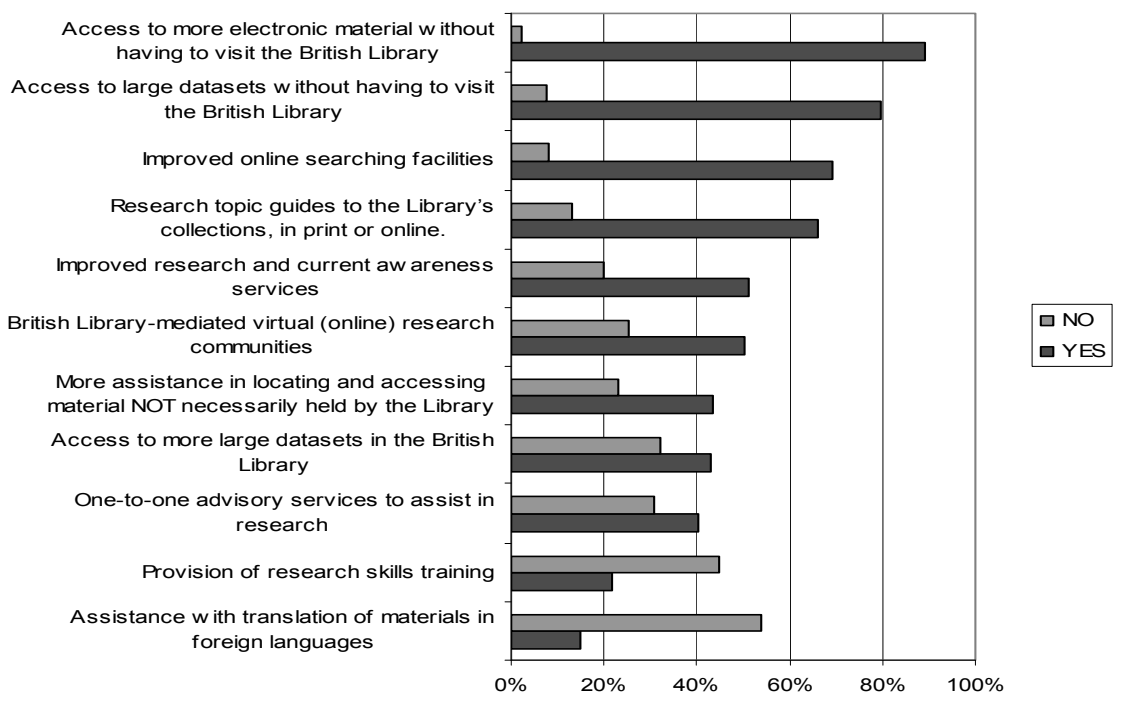

As we had anticipated, the study recommended we needed to improve publicity and promotion aimed at researchers, funders and university libraries to increase awareness and knowledge of the a BL. It suggested we establish BL-ESRC fellowships programme linked to ESRC Programmes and Networks to interpret and exploit the collections and open up the less accessible areas. Support for researchers was to be provided through the development of web-based topical and thematic guides for 'e-scholarship'. The report emphasised the need to work on the provision of remote access through licensing for holders of a BL Readers Pass and develop more detailed indexing of all new social science material, with metadata for content as well as provenance and form. A resource development programme was proposed, perhaps including retrospective cataloguing, but also exploring the possibilities of social tagging and web 2.0 technologies.

\section{THE STRATEGY}

The main purpose of Social Science Collections and Research within the British Library has been agreed as:

To support social science researchers by enabling access to, and exploiting, our collections and content; collaborating with key research and information service players; and, by connecting with the content and collections of others.

Within five years, our aim is to be playing a leading role in the management, provision, transfer and generation of information social scientists need and use. 
We will be actively exploiting aspects of the Library's collections through collaborative research-led activities. Building collections for future researchers is another theme. We also aim to become an active - and sought after - hub and facilitator for the exchange of ideas and information between researchers, practitioners and policymakers - both within and across communities of interest and sectors - as well as engaged in promoting the public understanding and awareness of the value and role of social science research. A key element of these activities will be to contribute to the development of the next generation of researchers.

This is against the background of a number of major fans who understand the point of the Library - whether as a primary or secondary research source and are very enthusiastic about collaboration, coupled with the requirement to build a new 'business' within the Library, developing our 'hook' for non-users and improving access to the collections. Crucially, improving knowledge and awareness of social science across the Library is essential.

In short, we do not believe it is enough for us to simply say that social science has reached the British Library and that we have enticed more readers through the front door. We believe have a key responsibility to contribute to knowledge exchange as well as knowledge creation, through collaboration and facilitation, making the best use of all the resources - from content to conference centre - available at the British Library. All our evidence suggests that many social science researchers are using libraries less and less as a source of information, but that the pulls of networking and sharing of issues, ideas and problems provide a more all-round attraction.

\section{Strategic Priorities}

Five strategic priorities are directing activity for the next three to five years:

- team creation and development;

- defining and developing a Social Science Collection;

- relationship and awareness building;

- improving accessibility; and,

- supporting, and working with, the research community to build capacity.

\section{Team creation and development}

Team development has taken place in three stages, starting with the appointment and establishment of the head of the department (September 2006), and concluding with the final phase of recruitment of content specialists in January 2008.

The head of department comes from a research background. The Library felt this was necessary to build credibility with the research community and improve the profile of the Library. The disadvantage of appointing someone without a library or information service background was the steep learning 
curve required on some of the more operational and methodological issues and systems.

The wider team was deliberately recruited to include a mix of skills, from those with a research background to those with qualifications in, and experience of, library and information services. Given the mix of potential users and the emphasis on engagement, interpretation and exploitation of content, selection was guided by the ability to communicate, influence, put together an argument and respond to challenge. We also looked for disciplinary knowledge as well as evidence of the ability to transfer and apply skills and experience to different environments and audiences.

The jobs were billed as 'content specialists' rather than 'curators', 'librarians' or 'subject consultants'. The purpose of doing so was to emphasise the outward facing aspects of the role, place emphasis on active knowledge and awareness of research issues and the needs of researchers, and on the ability to draw out relevant resources from the disparate collections held by the Library.

The designation of 'content specialist' has certainly been an advantage with external researchers and our ability to work with the range of researchers, information specialists and librarians has given the Library a tangible form. Less positively, it has caused some confusion and perhaps set the team apart from their colleagues within the Library, whose main primary responsibilities centre on the acquisition and curation of collection areas.

\section{Building a Social Science Collection}

Material of potential use for social science researchers is dispersed across the Library. Initial activity has concentrated on mapping it by discipline, regardless of format or geography. Content teams, with representatives from all curatorial departments, were formed to implement the content strategy and are supporting this activity. The scale of the task makes it essential to prioritise work within discipline. Mapping by research themes is also featuring where team members have an existing expertise.

\section{Relationship and awareness building}

This paper has highlighted the importance of engaging with the key social science research communities - both researchers and information providers. One mechanism has been focus groups and visits to researchers. On the whole, we have met with an enthusiastic response, with people happy to give their time and support our activity. There have been some exceptions, often defined by discipline, who simply do not think we are relevant to them. For the moment we are concentrating on those who are interested; this provides an easy - and fruitful way - of narrowing the scope of our activity. Additionally, we suspect that building momentum will itself attract the harder-to-engage and reach communities. 
With our general success and warm welcome we have become more and more conscious of the need to manage expectations - not promising more than we can deliver - while maintaining momentum. In this initial development phase it has been essential to get out there to as many institutions as possible; there is no doubt that this has been invaluable for the team in enhancing their awareness of researchers and the concerns of the research community. Our impression is that information professionals do not necessarily place always emphasis on listening to researchers and getting information on how they work, but more on pure information needs. As a personal view, it is much more difficult to engage with researchers without this level of understanding.

\section{Improving accessibility}

Improving accessibility to the collections and content of the Library - and collections elsewhere - is a key aspect of developing the social science strategy. As format and geography has taken precedence over subject in the British Library (whether topic, research theme or discipline), it would be a massive task to attempt to improve accessibility through cataloguing. In fact, within the Library as a whole we are devoting considerable efforts to improving our current cataloguing so the researchers in the not-too-distant future will be able to use a very wide range of search criteria. This leads to a key issue for the team, how to identify issues they can influence and separate them from those which are completely outside their control. Most cataloguing, for example, takes place in another directorate and location; decisions about the type of access software are made corporately; licensing arrangements for remote access are also corporate issues.

Within Social Science Collections and Research we have adopted various approaches to accessibility within our control. These include developing and expanding existing indexing and abstracting services, reviewing and updating existing collection guides and bibliographies according to discipline and research themes, and providing subject pages. We are exploiting the potential of events such as the 2012 London Olympics and the 2011 UK Census as a way of (a) highlighting the breadth and diversity of the work of social science researchers and (b) the multi-disciplinary potential of the Library's collections; and, exploring ways of enabling remote access to material. Activities include the development of a dedicated subject portal for management and business studies. The proposed subject portal will enable readers to access relevant subject material by working in collaboration with publishers but, importantly, will also include editorial provided by leading academics in the field and aim to make most use of the interactive ability of web 2.0. We have also held initial talks with the Economic and Social Data Service to open access to non-HE users registered as readers with the $\mathrm{BL}$; raising the issue of more general remote access for readers to material held elsewhere, including publishers. 
Identifying opportunities to exploit and interpret parts of the collection is another key activity. For example, we hold sound recordings of children's games and rhymes from the 1950s and 1960s. An initial idea to digitise this collection with the aim of improving access has developed into our collaboration in a successful research proposal looking at the role of children's play and games more widely. Additionally, we have taken advantage of three month placements funded by ESRC, where Phd students are based in the Library to carry out specific projects. Two students spent time with us in the summer of 2008; two more are booked in for 2009.

A key issue for the team - and, of course, the library world as a whole - is the capture and management of e-print formats. A particular focus is the move of UK government material to web publication. We are involved in a government-led initiative on web continuity ${ }^{10}$, and a feasibility study ${ }^{11}$ to assess the potential of establishing a virtual reference desk service for e-born government material. We will also be looking at the issue of e-born grey literature and are setting up a project to monitor publication and deposit over the next year or so.

\section{Supporting, and working with, the research community to build capacity}

One of the principles agreed by the British Library Board in 2006 was to focus on research skills training. However, the UK social science research community is relatively well provided for in this area - our scoping study and focus groups suggested that only a minority of researchers is interested in such provision. We have, therefore, widened this principle to encompass knowledge transfer, exchange and more general capacity building.

We have decided to place emphasis on the issues of methodological rigour, quality and validity, but we also want to promote the Library as a venue (actual and virtual) for multi-disciplinary, cross-profession/function knowledge exploration and information exchange. Initially our strategy has been to deliberately host events; building relationships, raising the Library's profile and opening the door to those who would not necessarily have thought to use us. This has also increased our profile and awareness of the Library as we feature on publicity material and give an overview on our activities.

Three examples of the variety of events follow. During the UK's annual festival of social science week in March 2008, we jointly hosted an event called Making policy - Making social research, attended by over 100 researchers. Our co-hosts were the Social Research Association. In July 2008, we hosted the British Sociological Association's Food Studies Group conference, providing an introduction to the Library to at least 150 researchers, and in November 2008 we ran an event to celebrate the $10^{\text {th }}$ anniversary of Welfare Reform on the $W e b$, an abstracting service for social policy researchers and practitioners. This took a workshop format, attended by around 40 practitioners and researchers, and debated the issues raised by a key note presentation from Pro- 
fessor Ruth Lister of Loughborough University on Social Citizenship, Human Rights and Poverty. An extensive programme was in place into 2009.

We are in the early stages of developing a long term studentship and fellowship programme, and supported two successful bids to the ESRC for seminar series', one on the influence of multi-modality and e-learning on the nature and format of doctoral theses in education and social science (with the Institute of Education and others); the other on corporate social responsibility (with CASS Business School and the University of Sheffield). Internally, members of the team are supporting the Library's Learning team with workshops for schools e.g. on history, citizenship, language, food and geography.

Another initiative includes working in collaboration to develop a public engagement programme (in the medium term) with the ESRC and the Academy of Social Sciences. The aim of this will be to contribute to activity around the theme of 'why research matters', essential in a climate where concerns over falling response rates for research and public unease as to confidentiality and security of personal information are both growing.

\section{CONCLUSION}

The purpose of this paper has been to give a flavour of, and outline, the challenges and opportunities involved in developing a cross-collection, multidisciplinary social science strategy in a national library.

Traditionally, the British Library's focus was on collecting and safeguarding the nation's cultural and historical memory, but the last decade has seen increasing emphasis on interpretation and supporting research. Consequently, the Library is moving toward a content-focused approach, but this process is new and challenging for the staff concentrated into format and geographical remits. A further challenge then arrived in the shape of Social Science Collections and Research, where a team with a clear requirement to look across the Library at content, access and interpretation, was added to the collections-focused structure. An essential, but not always easy, task for SSCR has been to develop relationships with our colleagues in the format and geographical collections.

Identifying material relevant to the social scientist held by the Library is a major task, added to by the fact that some of the non-users we have spoken to do not perceive the Library as of contemporary relevance. It has, therefore, been essential to break the process into bite-sized chunks, focusing on specific categories of researcher - here looking mostly at research themes as opposed to disciplines. We have concentrated, on identifying research issues which will facilitate this process, but there is a tight balance between developing thematic knowledge and mapping content as a whole by discipline. We have found it necessary to do both.

Looking at the make-up of the team, our recruitment strategy proved successful. It is clear that it was essential to have a team with (a) strong communi- 
cation skills and (b) an understanding of social science and social science researchers and (c) a subject interest. All have helped us develop links into the research community. The latter want to work with people who talk their language (which differs by discipline), know what the issues are, and can make the connecting links. At the same time the team includes members with long experience of the British Library; this has been of immense importance during our early development and while we are still 'the new kids on the block'.

One of the great joys of the British Library is the historical sweep of the collections and the fact that it contains both primary and secondary research data. For this reason we have (a) placed emphasis on collaboration, (b) prioritised capacity building around the rigour, validity and credibility of information and (c), focused on our potential as a hub for knowledge exchange. Academic libraries to some extent have a 'captive' audience and are driven by the interests of the academic staff in their institutions, though in the new digital world libraries as a whole are facing considerable challenges as to how to stay relevant to their users. No matter, at times we are envious of our colleagues in these institutions whose lives are guided by the rhythms of the academic year and linked to relatively homogeneous users.

As a national library we cannot rely on attracting social scientists without substantial 'hooks'; identifying these is, and will continue to be, a major challenge. At the same time, we have the opportunity to support efforts by the social science research community to raise public awareness of the role and importance of their research. We also have a key role to ensure that the Library's collections continue to include such a rich and diverse source of material for future researchers. We must therefore, be able to work both within and beyond disciplinary boundaries. The key challenge for the Social Science Collections and Research team is to manage this matrix of themes, disciplines and audiences to best effect.

\section{NOTES}

1. Information behaviour of the researcher of the future a ciber briefing paper, January 2008

2. The ESRC is responsible for the development of research and capacity building for UK social sciences, and a major funder of research activity in the UK university sector.

3. The UK government is a key funder of research, in the university sector, but also in the wider research community - including not-for-profit research institutes, the private sector, market research and so on.

4. The size of the social scientific academic community was estimated at between 14,000 and 30,000 in a report published by the ESRC in 2006. The lowest figure refers to research active staff in the core social sciences; the higher figure to academic staff engaged in teaching and research in all so- 
cial science related disciplines. According to the Higher Education Statistics Agency, in 2005, some 588,040 undergraduates were studying social science and 294,935 post-graduates.

5. The third sector includes charities and other similar not-for-profit organisations.

6. Examples of the numbers: in Government Social Research alone there are some 1,000 researchers in 20 government departments; the Social Research Association has around 1,000 members across central and local government, higher education, market research, in independent institutes and in the CVS.

7. A scoping study of the collections - use, awareness and future development, focusing on globalisation and population change - was funded by the ESRC and carried out in summer 2007. Tables Two and Three are from this study.

8. This includes researchers also involved in teaching.

9. From the research carried out for the Review of Social Science in the BL in 2003/04. In fact, our impression when carrying out the focus groups was that awareness had changed very little since this work took place. Having said this, usage of the social science reading room has increased at a greater rate than that in other reading rooms in 2007/2008. At least some of this increase must be attributable to our activity in the research community.

10. This is an initiative run by TNA on behalf of the Cabinet Office, which has developed a solution to the issue of 'broken links' across government. We are working with the project team to ensure that the short term solutions for the broken links also facilitate our role in long term preservation and maintaining the continuity of the OP collection.

11. With the London School of Economics and Oxford University's Social Science Library.

\section{BIOGRAPHICAL STATEMENT}

Jude England joined the British Library in September 2006 as Head of Social Science Collections and Research. This is a relatively new post, responsible for the development of the Library's social science strategy. Before joining the Library, Jude's career was spent in research and consultancy, specialising in social policy research and employee relations consultancy. Her career started at the Office of National Statistics; includes time as a researcher in the higher education sector - at LSE and the University of York; in government - at ACAS (the Advisory, Conciliation and Arbitration Service); and in the not-for-profit sector - at the National Centre for Social Research, as well as in private sector consultancy. Most recently Jude worked as an Associate Director with a public policy research consultancy house - ECOTEC Research and Consulting Ltd. 